Sādhanã, Vol. 12, Part 3, March 1988, pp. 229-234. (C) Printed in India.

\title{
Development of solid propellant technology in India
}

\author{
M R KURUP, V N KRISHNAMOORTHY and M C UTTAM \\ Indian Space Research Organisation, Department of Space, SHAR \\ Centre, Sriharikota 524 124, India
}

\begin{abstract}
Space research in India started in 1961 when a two-stage rocket was launched from Thumba on 21 November 1963. On the sudden passing away of Dr. Vikram Sarabhai, the originator of the Indian space programme, Prof. Satish Dhawan became the second chairman of ISRO. His stewardship saw it through its teething troubles on to launching of several R \& D tasks and growth of several ISRO Centres. Major breakthrough in many hightech areas took place during this period. High energy composite solid propellants were developed, characterized and produced at the Vikram Sarabhai Space Centre and at the Sriharikota Centre. Exotic fuel binders such as HEF-20, Polyol and HTPB for these propellants were also developed in ISRO as part of the indigenisation programme. The Satellite Launch Vehicle-3 (SLV-3) conceived in the early seventies, was fitted with four stage motors filled with solid propellants made in ISRO's own plants. These facilities, including critical process equipment, have come up as a result of ISRO's indigenization efforts. The SHAR Plant known as SPROB has been further augmented to produce large propethant grains to meet the needs of the Polar Satellite Launch Vehicle (PSLV).
\end{abstract}

Keywords Solid propellant; HTPB-based propellant; rocket motor; propellant binder.

India took her first step into the space age in 1961, when the Government of India entrusted the study of the subject of space research and peaceful applications of outer space to the Department of Atomic Energy (DAE). Next year, DAE set up the Indian National Committee on Space Research (INCOSPAR) to organise the space programme. On 21 November 1963 a 2-stage Nike-Apache rocket was successfully launched from Thumba and the Thumba Equatorial Rocket Launching Station (TERLS) became operational, thereby heralding the dawn of the Indian Space Programme. The Indian Space Research Organisation (ISRO) came into being in 1969. In 1972 the Government of India set up the Space Commission and created the Department of Space with ISRO under its purview. 
Dr. Vikram A Sarabhai, the visionary who was the originator of the Indian space programme passed away suddenly in 1971. Prof. Satish Dhawan, who was then Director IISc, became the second chairman of ISRO. His stewardship of the space programme from 1972 to 1984 , saw it through its teething troubles on to launching of a wide variety, of $\mathbf{R} \& \mathrm{D}$ tasks, growth of four ISRO centres, success of satellite and launch vehicle projects and finalization of a profile for the decade of the 1980s. Major breakthroughs in several high technology areas took place during this period. We will describe below the success achieved in the area of solid propellants.

With the acquisition of a limited technology transfer arrangement with France for sounding rockets, ISRO had started manufacturing composite propellants based on PVC resin from 1968 onwards. However, the 'Why' and 'How' had to be understood and more energetic propellants for satellite launch vehicles had to be developed. The Propellant Engineering Division (PED) and an R \& D section in the Rocket Propellant Plant (RPP) were assigned the responsibilities.

Composite propellants contain a crystalline oxidiser, a polymeric fuel binder in a liquid state, a metallic fuel and a curative as the main ingredients. There are a number of minor additives to impart specific properties to the cured propellant. Ammonium perchlorate is the universally accepted oxidiser. Atomised aluminium powder is the metallic fuel generally employed. Polyurethane- and polybutadienebased binder systems are the common ones used for a long time, but there are variants of each of these two systems: e.g., CTPB, PBAN and HTPB. These binders are not easily available and it became essential to develop them. ISRO's R \& D efforts in this direction resulted in the development of high energy binders like Polyol and HEF-20. Later on for larger motors the choice fell on HTPB. This too has beer successfully developed and know-how transferred to industries for large scale production.

As is usual a thorough literature survey preceded our efforts in the development of solid composite propellants. Since the field is a highly guarded one we had to analyse the published material carefully and accept them with caution. Ternary diagrams were drawn and computer programmes developed to arrive at theoretical compositions. With the large number of variables in materials and percentage compositions, adopting the above procedure helped in reducing the number for experimentation to a manageable level. The so-called test tube level trials then followed. During this phase some of the formulations had to be rejected based on processing problems, and safety considerations. The shortlisted compositions were then tried out in $\mathrm{kg}$-levels in mixers having the same geometry as in industrial scale operations. Control parameters initially fixed were monitored. The slurry characteristics, viscosity build-up, curing pattern and mechanical properties were determined from propellants cast in cartons. Measurement of the ballistic properties was done in small motors which gave a good idea of the energetics of the system. This was followed by thorough characterization of the final propellant, for its rheological, mechanical, thermal and ageing properties, its performance, and the associated hazards.

The mechanical properties and failure behaviour of HTPB-based propellants have been studied in detail at ISRO. Figure 1 shows the uniaxial failure boundary plotted for one of our propellant systems currently in use. Here the maximum value of the strain at maximum stress $\left(E_{m}\right)$ is found to be $45 \%$. The limiting value of the strain 


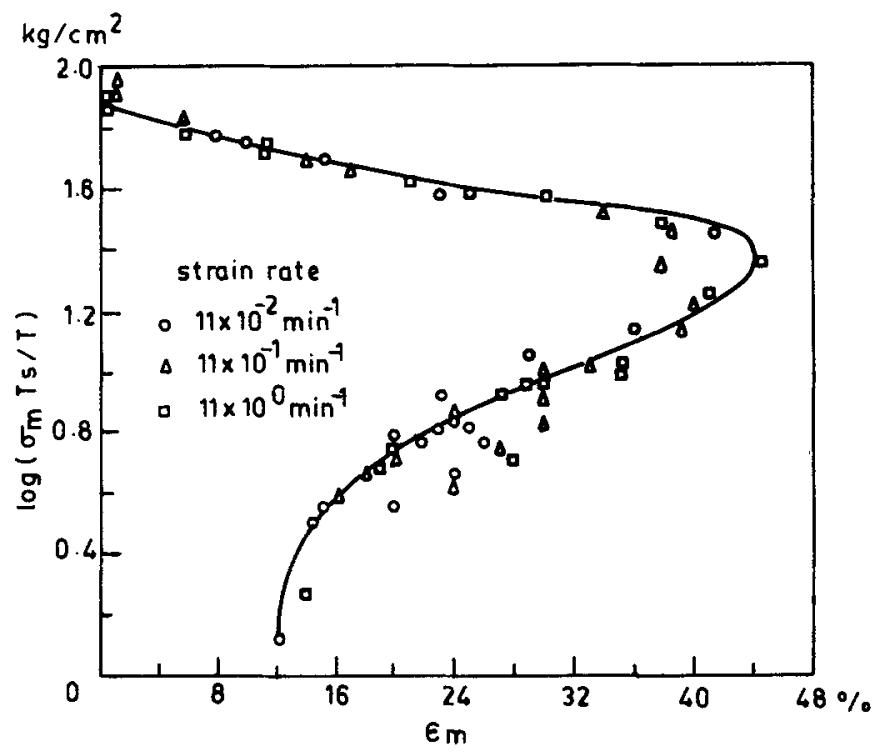

Figure 1. Uniaxial failure boundary.

beyond which the propellant will eventually fail either in relaxation or in creep is found to be $12 \%$. Figure 2 is a master stress-relaxation modulus curve reduced to $-15^{\circ} \mathrm{C}$ for the same propellant. Relaxation modulus values are deduced from the slope of the master stress-strain curve. The glassy modulus of propellant at very high strain rate or at very low temperature $\left(E_{g}\right)$ and the equilibrium modulus of propellant at very low strain rate or very high temperature $\left(E_{e}\right)$ can be found by extrapolation to very low and very large time scales, respectively. Variation of yield stress with temperature and time is shown in figure 3. As time elapses, the temperature at which the yield stress is minimum shifts to lower values. For example at 4 hours of time, $50^{\circ} \mathrm{C}$ is the temperature of minimum yield stress for this

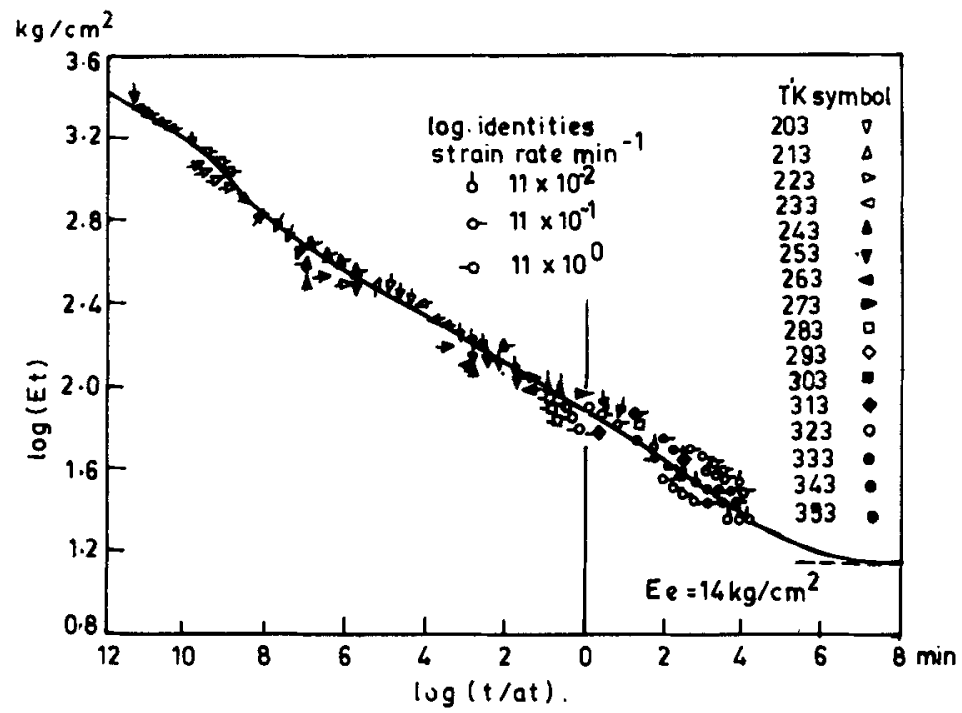

Figure 2. Master stress-relaxation modulus curve reduced to $-15^{\circ} \mathrm{C}$. 


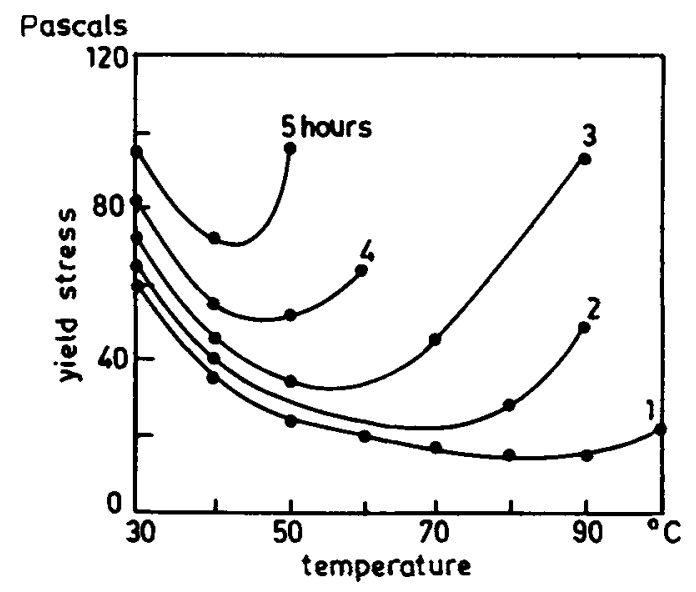

Figure 3. Variation of yield stress with temperature.

propellant. Similar is the case with the consistency index $k$, which is one of the parameters for describing the rheological property of slurry, plotted in figure 4 . A minimum value of $k$ is shown at a particular temperature which shifts to lower values with lapse of time. Auto ignition, spark, friction tests etc., characterize the propellant from the hazard angle. Ultimately the composition chosen must be feasible for industrial production with available equipment and known methods without causing extreme hazards to property and human life. Since most ISRO rocket motors are of the case-bonded type (i.e. the propellant is cast inside an insulated and lined rocket chamber and during curing the grain sticks to the wall), the thermal properties are also to be ascertained and process conditions suitably adjusted to ensure defect-free grains. Coefficient of linear expansion, thermal

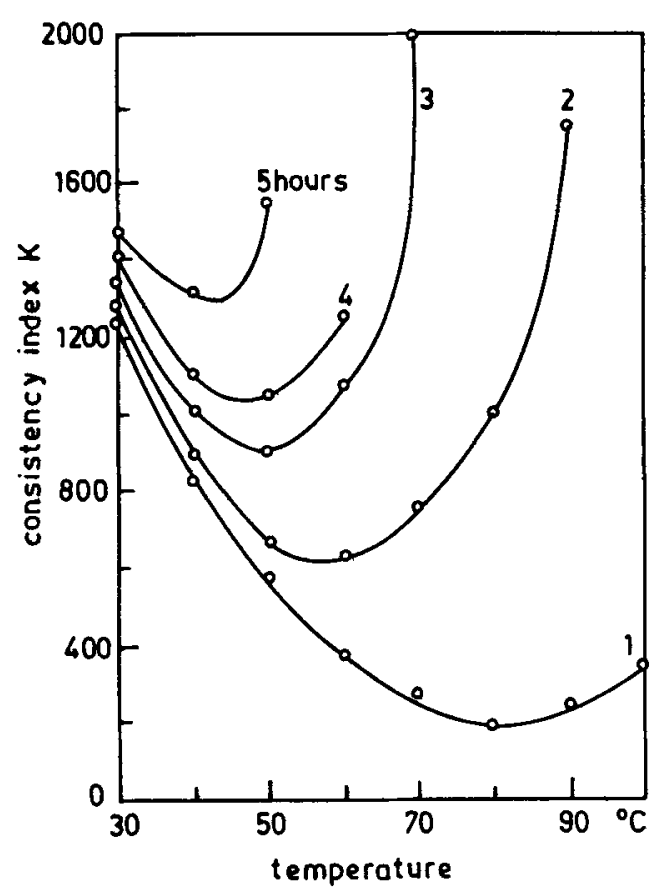

Figure 4. Variation of consistency with temperature. 
Table 1. Dimensions and other parameters of the 4 stage motors of the SLV -3 configuration.

\begin{tabular}{|c|c|c|c|c|}
\hline Parameter & Stage 1 & Stage 2 & Stage 3 & Stage 4 \\
\hline Diameter $(\mathrm{mm})$ & 1000 & 800 & 800 & 650 \\
\hline Length $(\mathrm{mm})$ & 8700 & 4850 & 1620 & 860 \\
\hline $\begin{array}{l}\text { Rocket case } \\
\text { material } \\
\text { Propellant }\end{array}$ & 15 CDV6 & 15 CDV6 & FRP & FRP \\
\hline $\begin{array}{l}\text { binder } \\
\text { Specific }\end{array}$ & PBAN & PBAN & HEF-20 & HEF-20 \\
\hline $\begin{array}{l}\text { impulse (s) } \\
\text { Propellant }\end{array}$ & 254 & 268 & 278 & 284 \\
\hline weight $(\mathrm{kg})$ & 86000 & 32000 & 1080 & 320 \\
\hline
\end{tabular}

conductivity/diffusivity, specific heat, and glass transition temperature are determined experimentally. Static tests with adequate instrumentation confirm the ballistic performance of the formulations.

It was decided in the early seventies that a satellite launch capability, though on a modest scale, must be acquired by ISRO. Looking at the existing technologies and also the immediate prospects of developing new technologies, it was very clear that the propulsion units will have to be solid motor based. The SLV-3 configuration with 4 stages of solid motors was thus born. The dimensions and other important parameters of these stage motors are given in table 1.

For those of us engaged in development of solid propellants this decision was a morale booster. We set about designing equipment and facilities both at RPP and a new and much bigger plant at SHAR. Both these facilities were realised in time for the SLV-3 programme and except for less than $15 \%$ of high tech equipment the entire scheme was conceived and implemented by ISRO engineers and scientists. The SHAR plant known as SPROB has been further augmented for PSLV demands and we have today the capability to produce single grains measuring $3 \mathrm{~m}$ in diameter and capable of carrying 25-30 tonnes of propellant. It compares well with similar facilities anywhere in the world. In terms of propellant properties such as specific impulse, burn rate, density and mechanical properties also ISRO is very close to the frontiers.

The 'deadly parallel'* approach promoted by Prof. Dhawan in the case of propellant $R \& D$ paid rich dividends and as a result we are today very close to the best in the world in this strategic item. His policies encouraged us to diversify, especially on the raw materials and in the indigenization of critical equipments. Engineering a production unit at Alwaye for ammonium perchlorate, building a Propellant Fuel Complex at Thumba, indigenizing equipment like perchlorate grinder and vertical mixer and development of a $4 \mathrm{MeV}$ Linear Accelerator with assistance from the Tata Institute of Fundamental Research are some of the important contributions towards self-reliance in Solid Propellant Technology. ISRO

\footnotetext{
* This is a management term for taking up parallel activities to achieve the same objectives, deliberately
} initiated in the critical areas for healthy competition and assured outcome. 
can today build a solid booster carrying hundreds of tonnes of high energy solid propellant.

The inspiration and guidance for this extraordinary effort have come mainly from Prof. Dhawan, and we are happy to dedicate this paper to him. 